مجلة علوم الإنسان والمجتمع......................................................

\title{
الإعلام الجديد والتحولات الديمقراطية
}

الدكتور : سليمان محمد عمر منصور

جامعة الزاوية، ليبيا

الملخص:

صار للأعلام الجديد دورا هاما ورئيسا وفاعلا في سياق التحول الديمقراطي

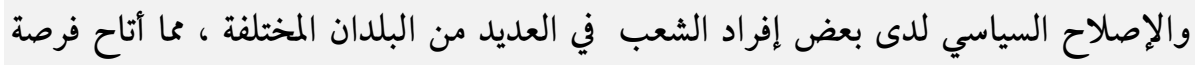

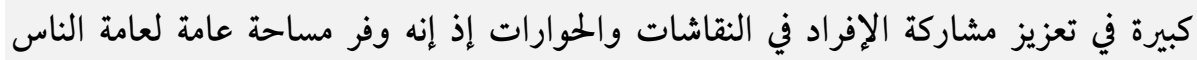

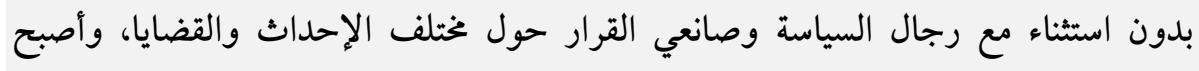

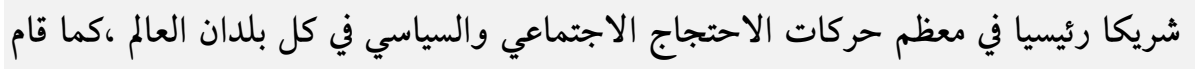

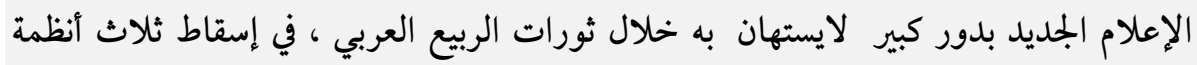

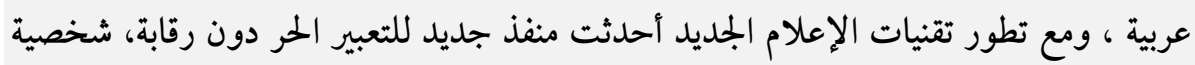

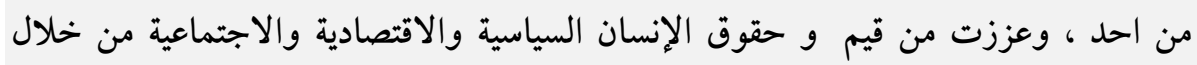

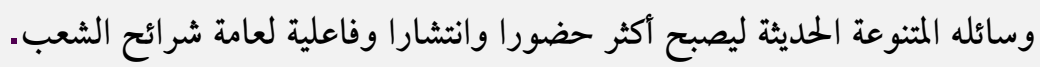

\section{Abstract:}

New Media has become an important role and the president and actor in the context of democratization and political reform among some of the people in many different countries, which provided a great opportunity to promote the participation of individuals in the discussions and dialogues, as it provided a public space for the general public, without exception, with politicians and decision makers on various events and issues, and has become a major partner in the most social and political protest movements in all countries of the world, as the new media played a major role for the sizeable enough during the Arab Spring, in dropping three Arab regimes, with the development of new media technologies created a new outlet for free expression without censorship, personal of one, and reinforced the values and political, economic and social rights through the means of modern diversified to become more visible and widespread and effective for the general population segments.. 
يلعب الإعلام دورا مهما في المجتمع بصورة عامة، ودورا استثنائيا في

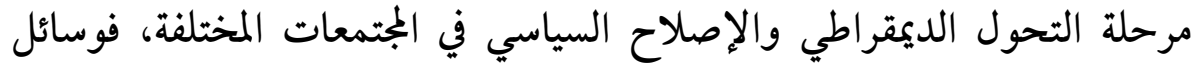

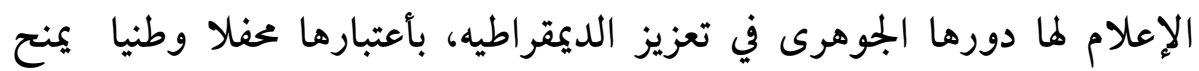

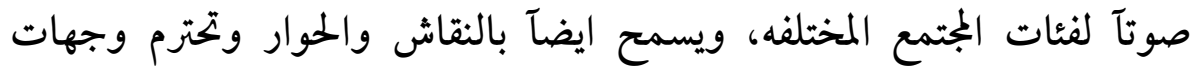

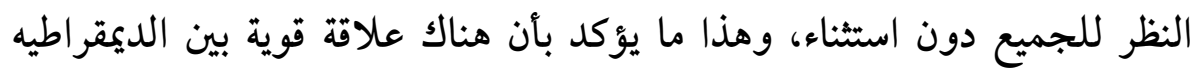

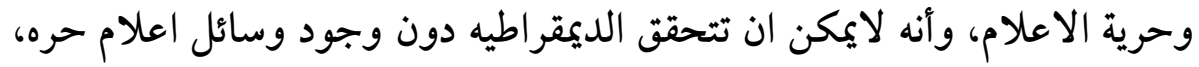

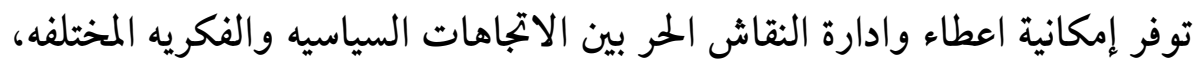
والاعلام الفعال الذي يفرز الديمقراطيه ويؤثر فيهاويتأثر بها.

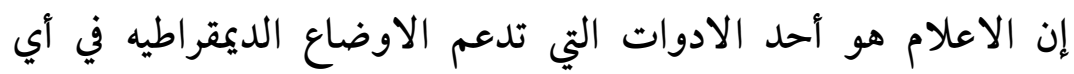

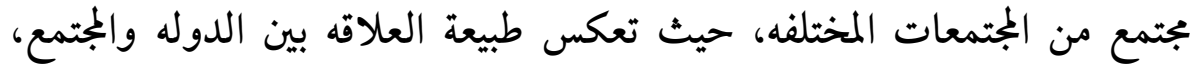

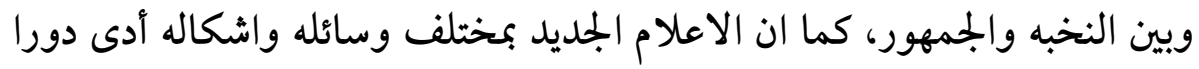

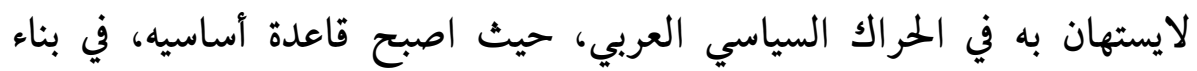

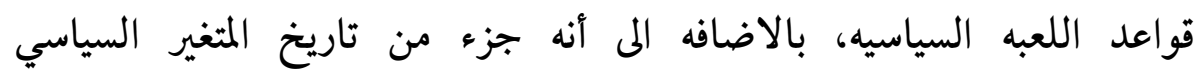
والاجتماعي مقابل تدهور وتقهقر الاعلام التقليدى الرسمي.

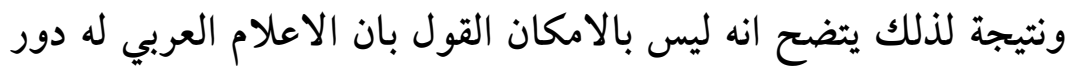

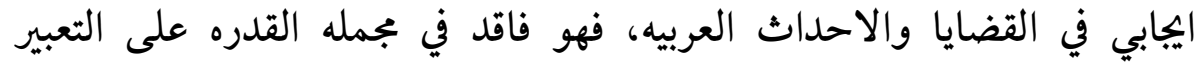

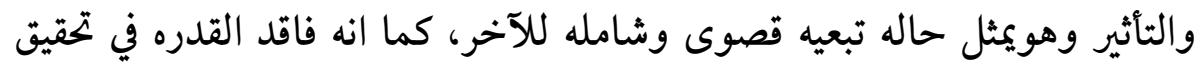

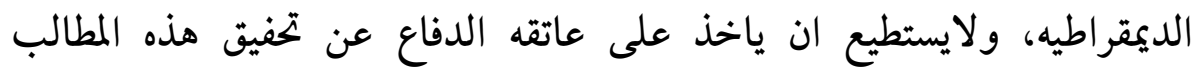

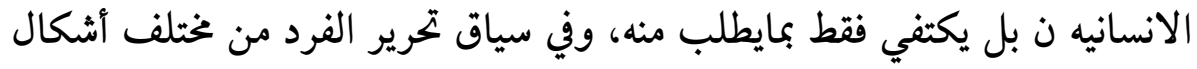

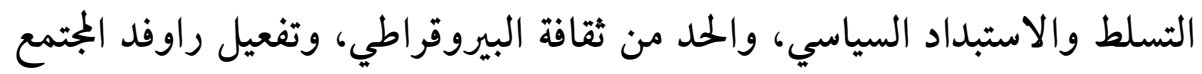
المدني بتوفر الماده المعلوماتيه وكسر قيود الاحتكار الممارس عليه وليه

كل هذه الغايات قد تؤدى دورآ هامآ في عملية الحراك الديمقراطي

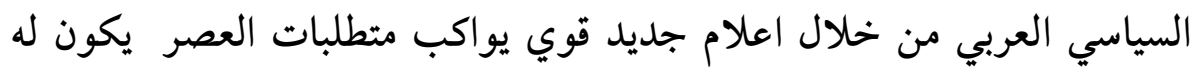




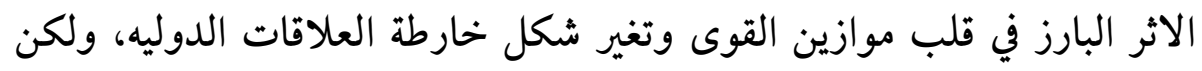

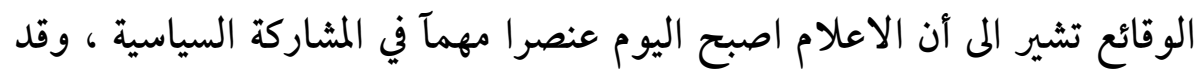

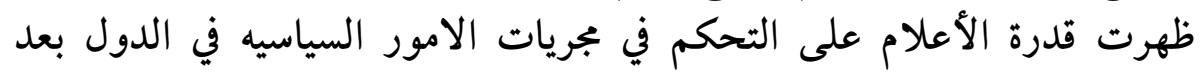

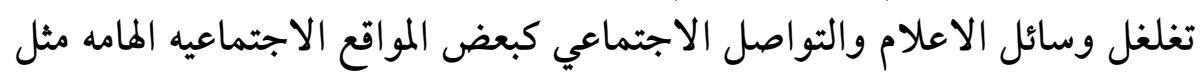

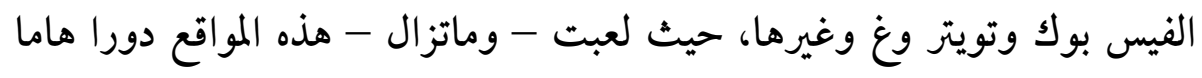

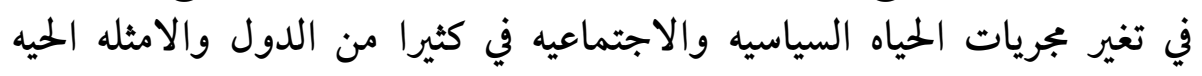

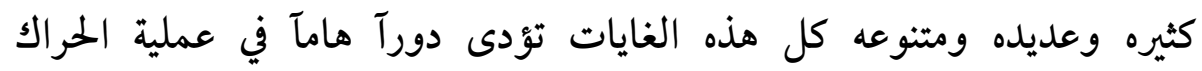

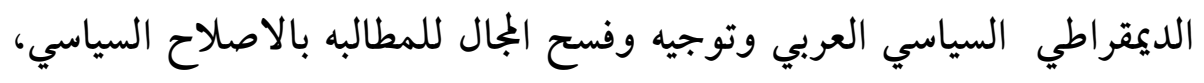

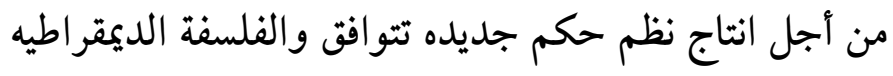

وهكذا فإن البحث سينطوي على ثلاثة مباحث فأما المباحث فسترد مرتبة

ومعنونة على النحو التالي :- وهن فان البحث

المبحث الأول :-

تعريف الأعلام ثانيا: مفهوم الأعلام في الاصطلاح ثالثا: تعريف الأعلام الجديد

المبحث الثاني:-

أولا:-استخدام وسائل الأعلام الجديد في تعزيز القيم الديمقراطية. ثانيا:- دور القنوات الفضائية العربية في تحقيق الديمقراطية. ثالثا:- دور شبكة المعلومات الدولية في المشاركة الديمقراطية. البحث الثالث :دور وسائل الأعلام الجديد في التحول الديمقراطي في دول الربيع العربي. وأخيرا وليس آخرا فهناك خاتمة وتوصيات ونتائج تتعلق بالبحث 
ومن خلال هذه المقدمة المتواضعة سنحاول التركيز على دور الأعلام الجديد ودوره في عملية التحول الديمقراطي في العالم العربي.

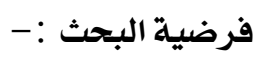
ينطلق هذا البحث من الفرضيات التالية :$\checkmark$

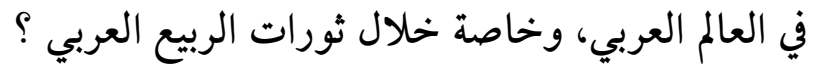
ل ماهي السياسات الاحترازيه التي وضعها الأعلام الجيد في نشر سياسته

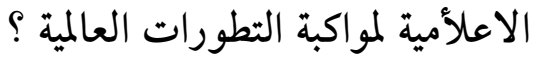
ح كيف صار الأعلام الجديد خال من كل القيود والرقابة، على عكس لإس الأعلام التقليدي ؟ إن

\section{أشكالية البحث :-}

تتمحور اشكالية البحث حول دور وسائل الأعلام الجديد، وفي المقدمة

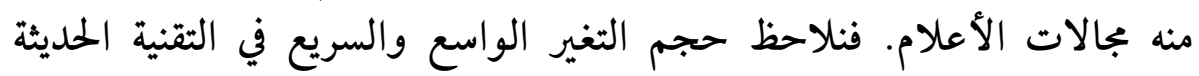

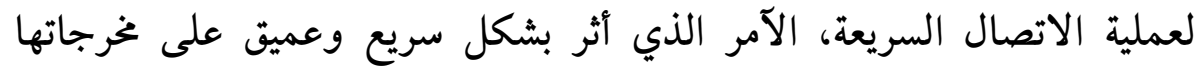

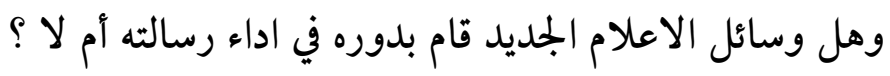
أهمية البحث:-

يتم فيه تحليل معالجة وسائل الأعلام الجديد والتطورات التي حدثت خلال السنوات الماضيه وأثرها على مرحلة التحول الديمقراطي والأصلاح السيا سي في

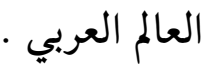
ل تسليط الضوء على القضايا الفكرية والسياسية المطروحة في التعبير عن مشاكلها .

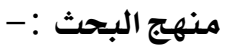


استخدم الباحث المنهج التحليلي الوصفي، ونم التركيز على البحث من

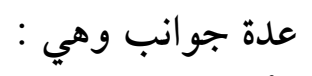

الأعتماد على المصادر وهي الكي الكتب والدراسات السابقة والبحوث المتعلقه بالموضوع والمقالات وكذلك شبكة المعلومات الدولة الماتل

تعريف الأعلام

$$
\text { مفهوم الإعلام في اللغة :- - ماعل }
$$

الأعلام قديم الإنسان وقدم الجمتمع البشرى - فمنذ أن وجد الإلـان الإنسان

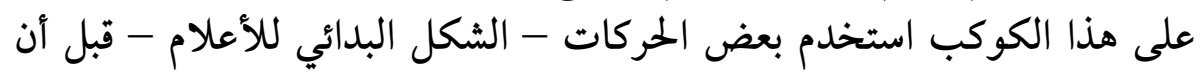

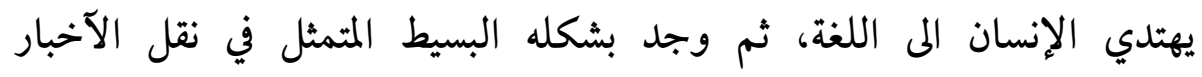

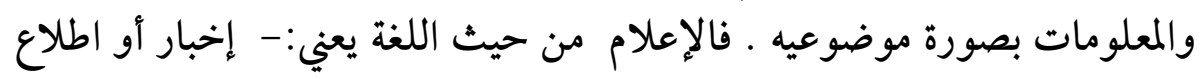

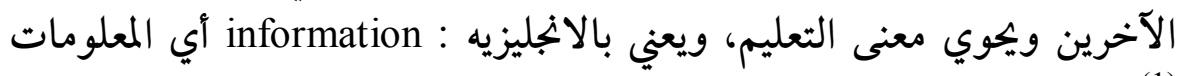

وجاء في معجم محيط المحيط "بطرس البستاني "الأعـلام في اللغــة : مصـدر

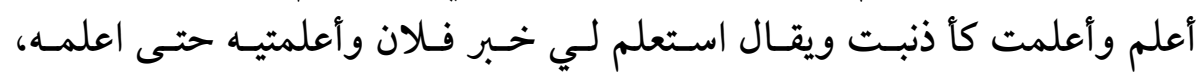

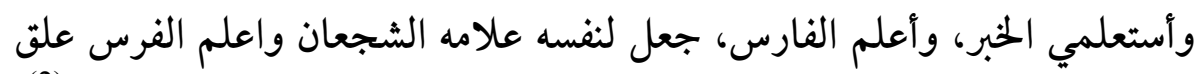

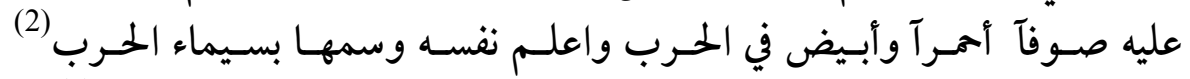

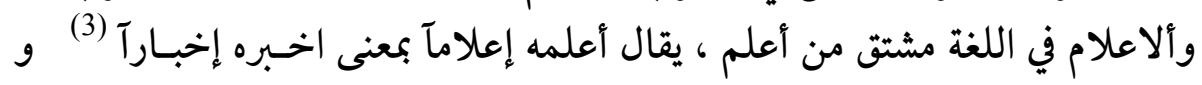

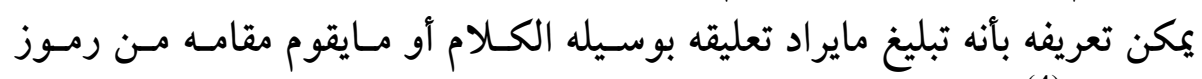
وإشارات (4) ثانياً: مفهوم الاعلام في الاصطلاح:-

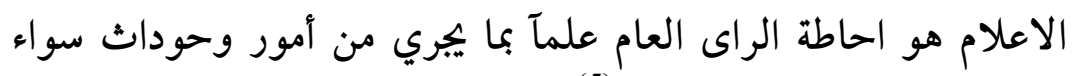

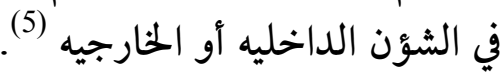

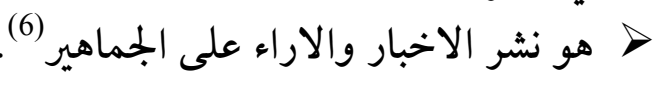

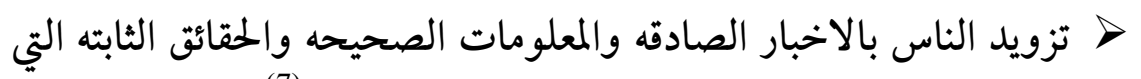
تساعدالناس على تكوين رأي صائب في واقعة معينه (7). 


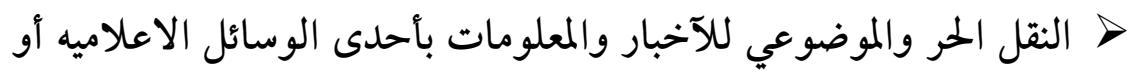

نقل الاخبار والوقائع بصوره صحيحة لالآنيار والمعلمات

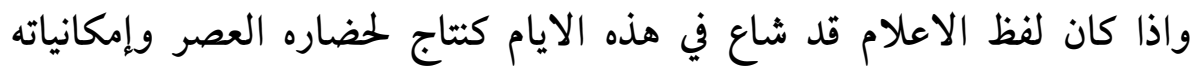
ألاتصاليه فإن ذلك لا يعنى أن ألأعلام ظاهره حدان الإيثه.

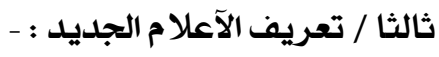

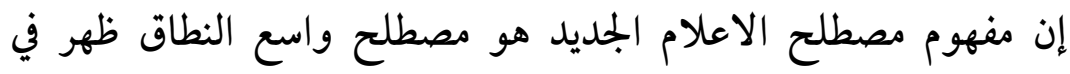

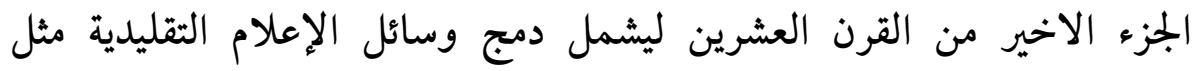

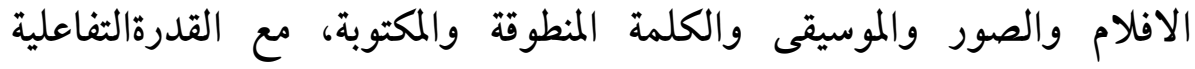

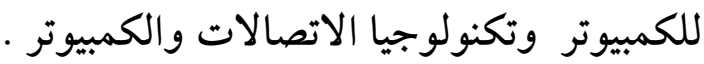

ويعرف قاموس التكنولوجيا الرفيعه HiJh-Tech Dictionary الإعلام

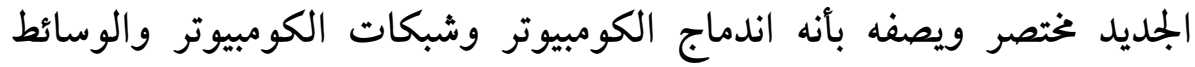

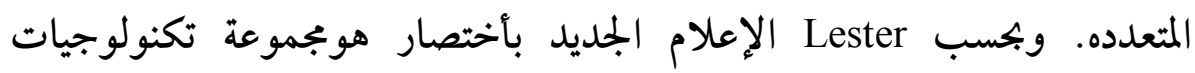
الاتصال التي تولدت من التزاوج بين الكومبيوتر والوسائل التقليديه للإعلام الإمبام

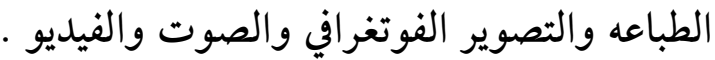

ويعرف قاموس الانترنت الموجز

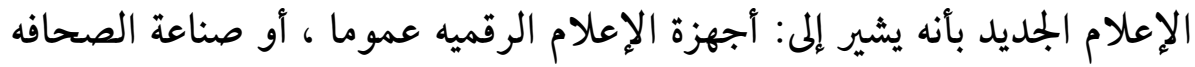

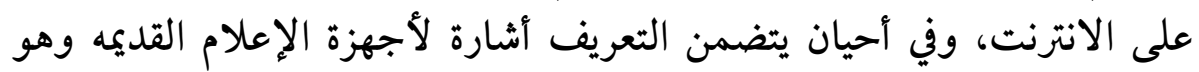

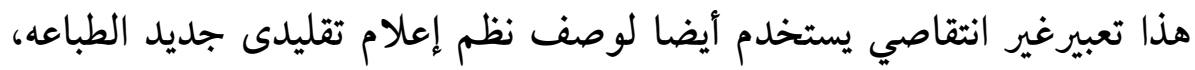

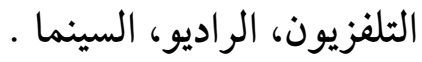

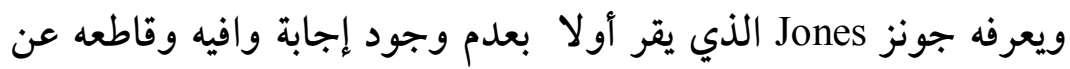

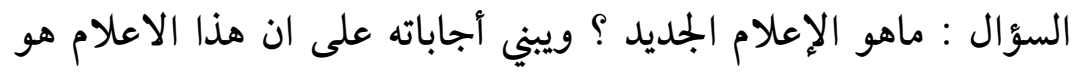

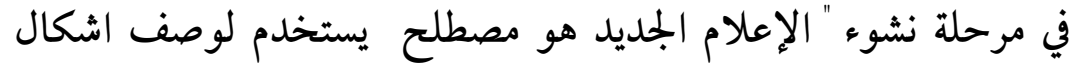

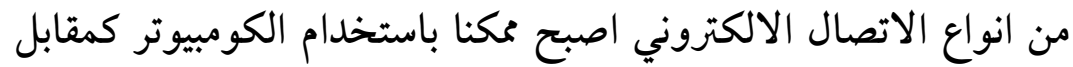

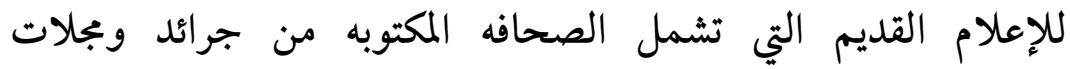

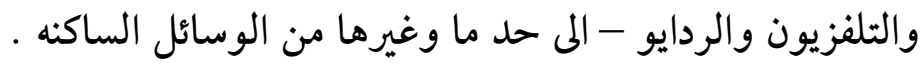


وتضع كلية شريديان التكنولوجيه Sheridan تعريفا عمليا للإعلام الجلديد بأنه :-

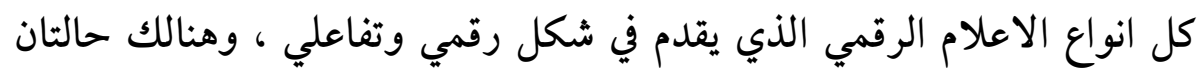

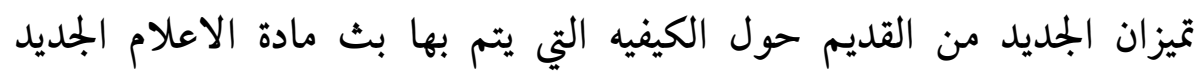

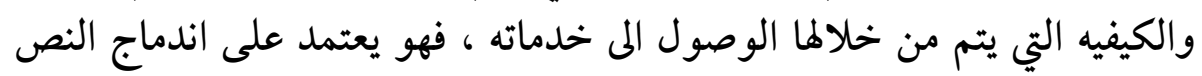

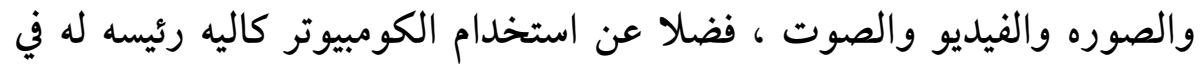

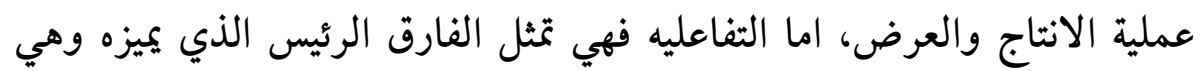

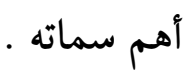

أما تعريف البهبهاني والبرغوثي: ان ألأعلام الجديد عمليه عرض العالم

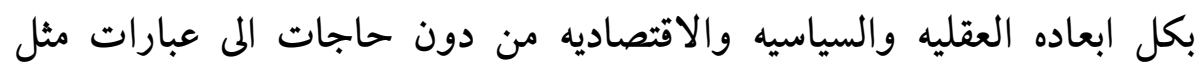

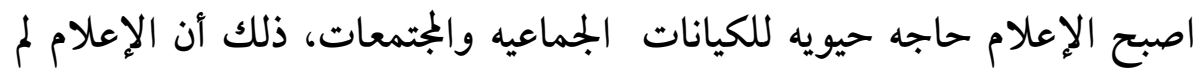
يصبح كذلك، بل كان كذلك منذ كان، أما تقنيات بثه واستيداعه واسترجاعه واعه فهي تطورات ماديه جاءت ضمن سياق التطور الانساني الذي يجعل كماليات اليوم ضروريات الغد.

وهناك مصطلح حديث، يتضاد مع الإعلام التقليدي ، لكونها لإعلام

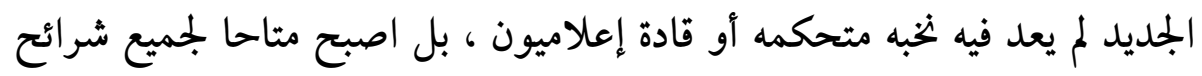
الجمتمع وافراده الدخول فيه واستخدامه والاستفاده منه طالما تمكنوا واجادوا أدواته.

من جملة التعريفات السابقه يمكن القول أن ألأعلام الجديد يشير الى حالة

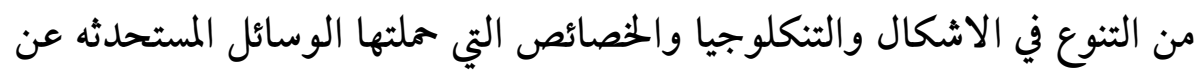

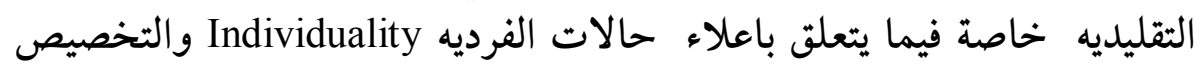

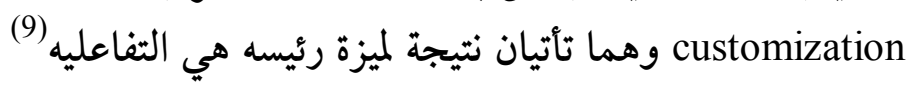

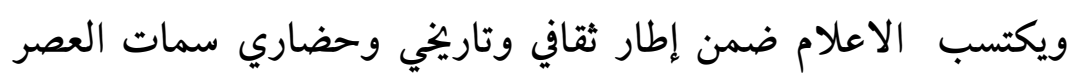

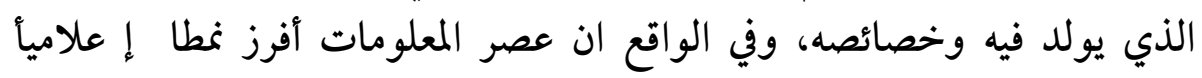

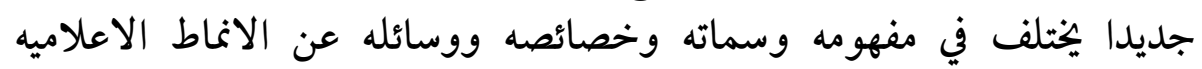

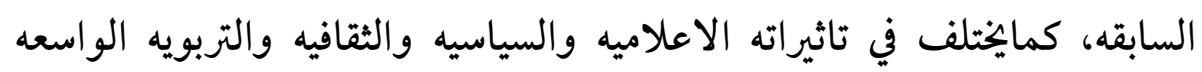




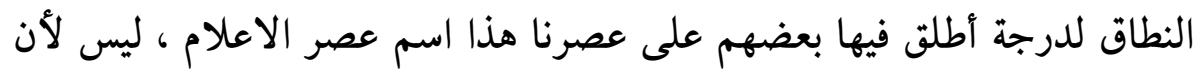

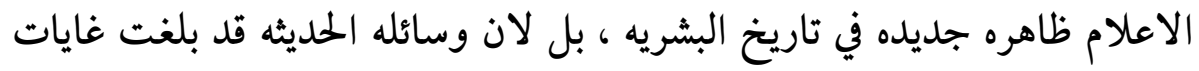

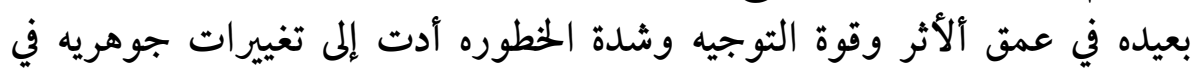
دور الإعلام ، وجعلت منه محورا اساسيا في منظومة المجتمع (10).

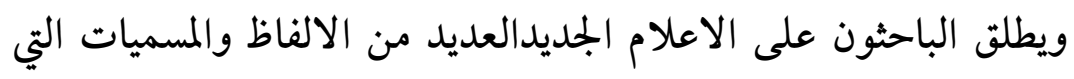

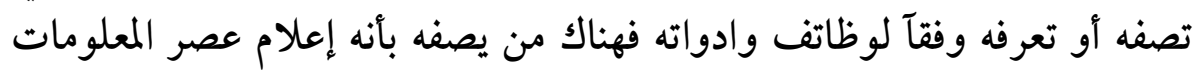

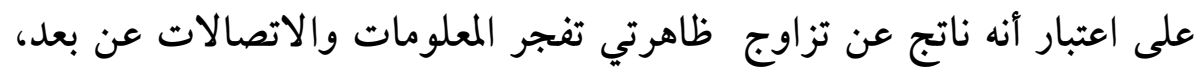

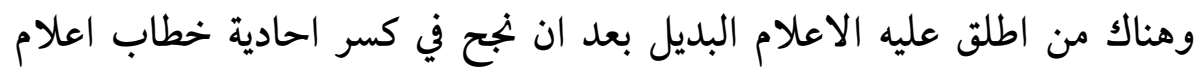

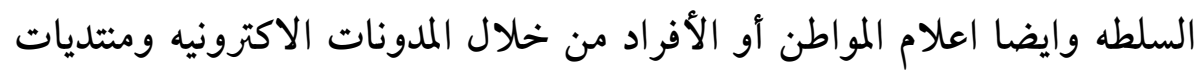

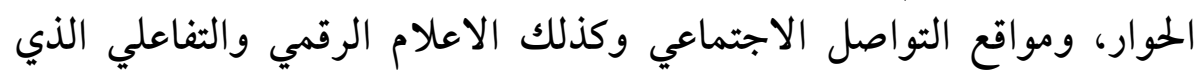

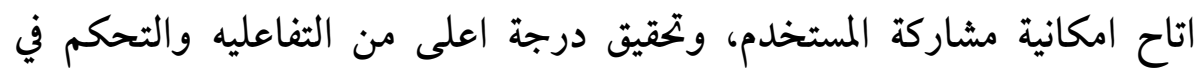

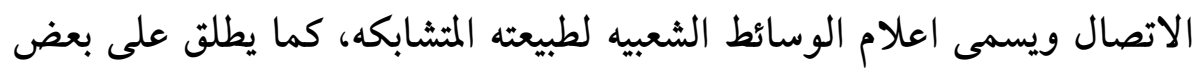

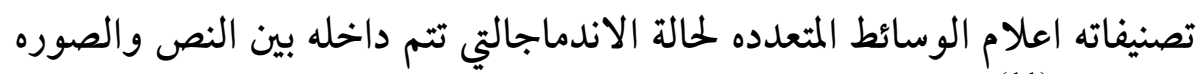
والفيديو." (11).

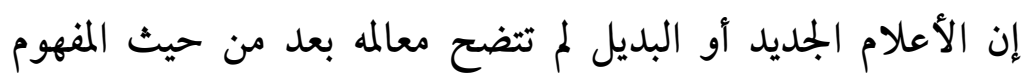

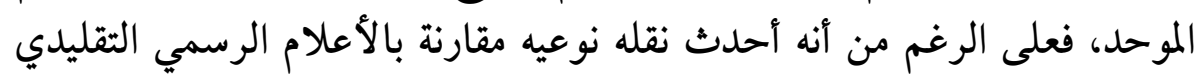

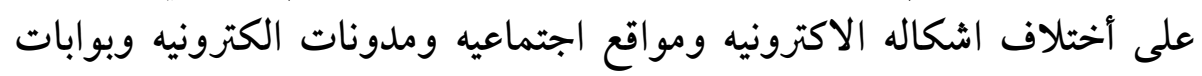

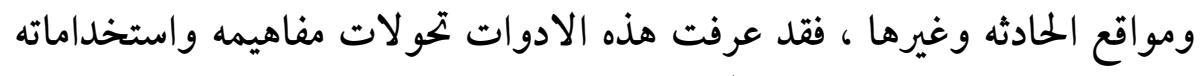

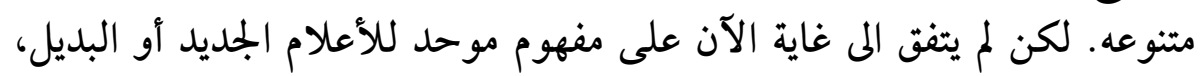

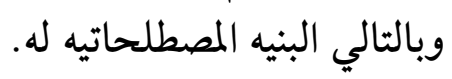

المبحث الثاني:أستخدام وسائل الإعلام الجديد لتعزيز القيم الديمقراطيه لإليه

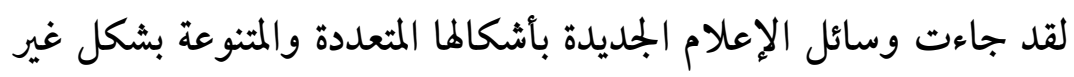

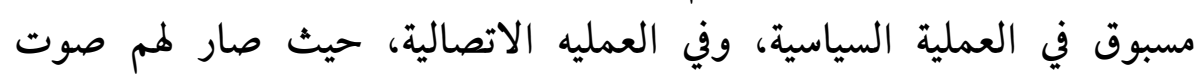

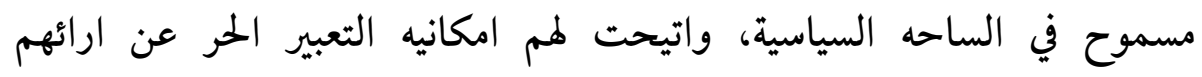

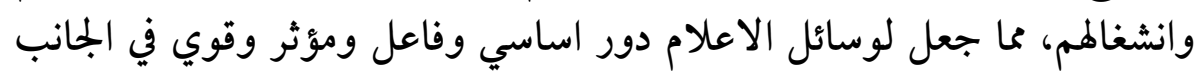


الديمقراطي بشكل مباشر وغير مباشر في المبادى الانسانية وبشكل سلطة معرفيه

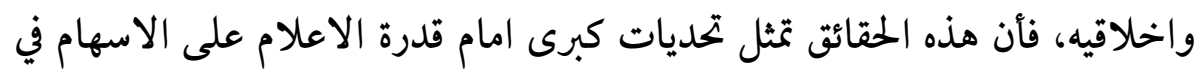

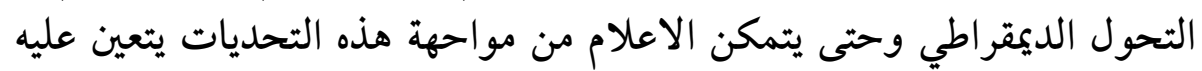

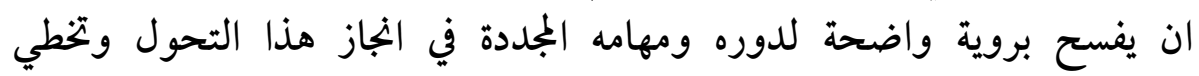

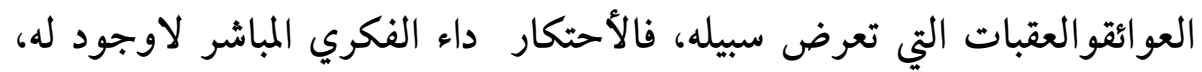

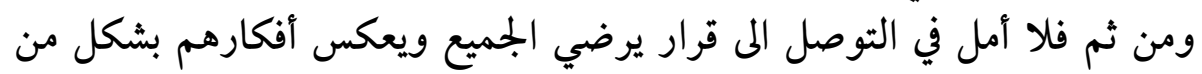

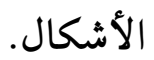

واذا كان يتبادر الى الذهن أن النظم الديمقراطيه المعاصره تستطيع دائما

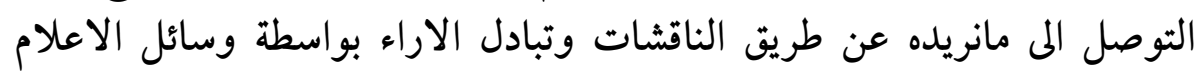

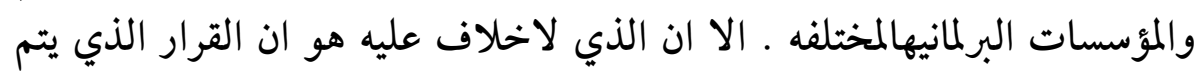

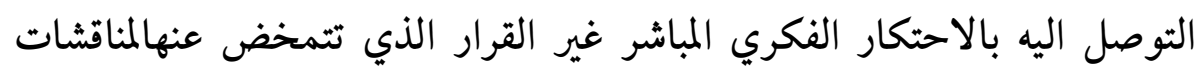

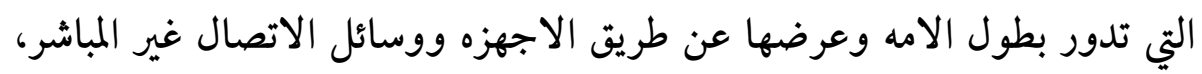

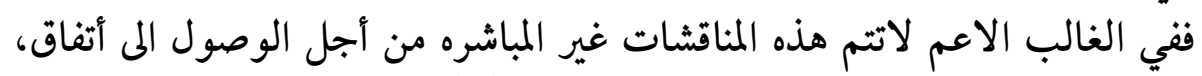
بل من أجل الحصول على تأييد اغلبية الجماهير (12).

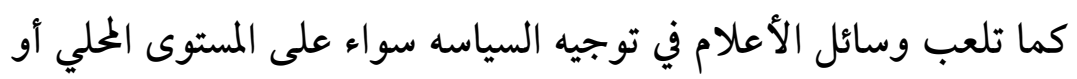

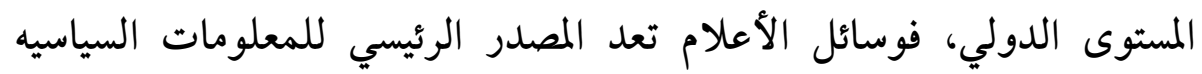

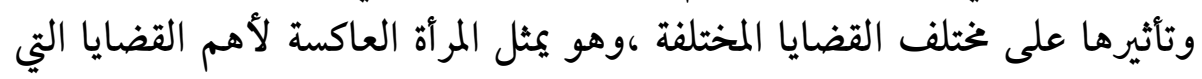
تثير الساسة وصناع القرار، فضلآ عن رفع وعي المواطنين بأهمية المشاركة

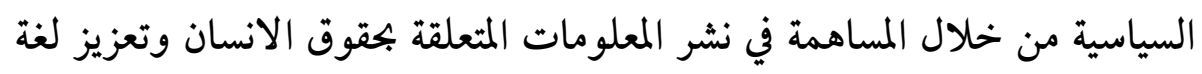

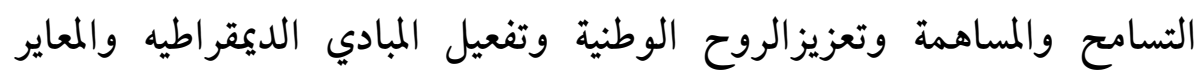

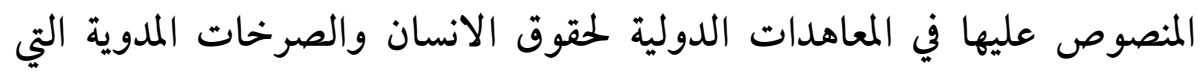

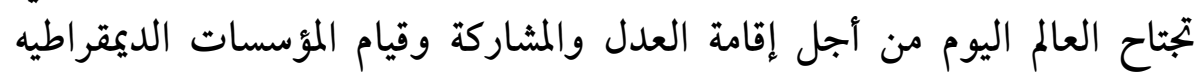
وسيادة القانون.

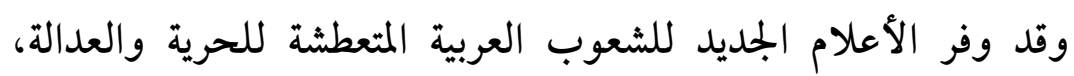

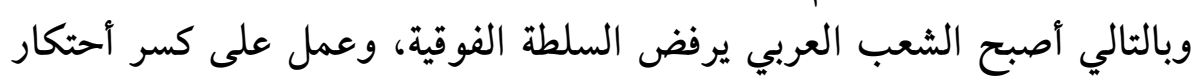




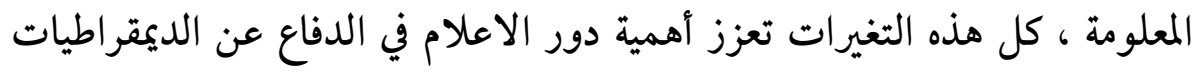

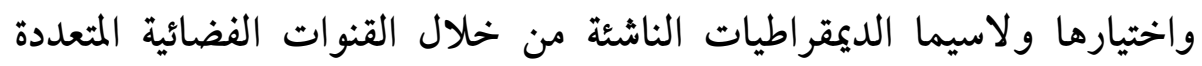

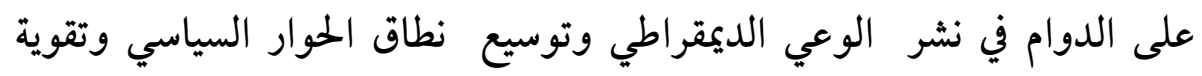

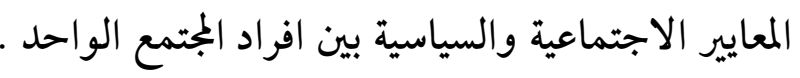

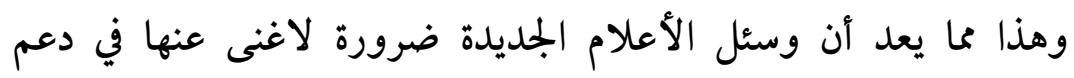

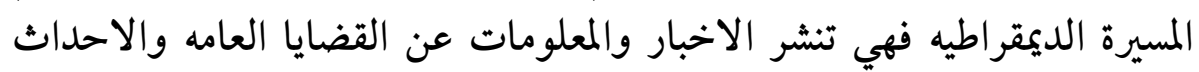

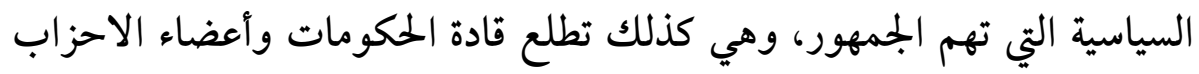

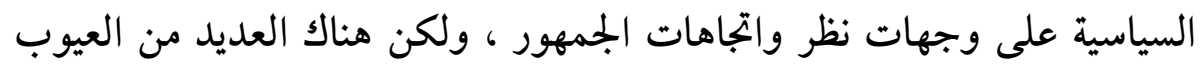

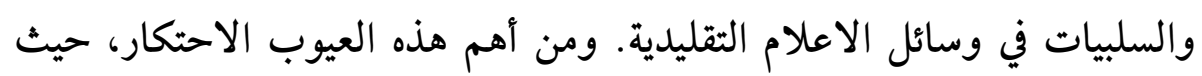

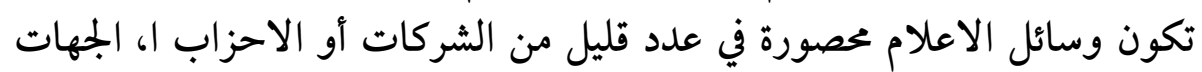

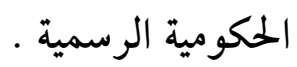

ما ينتج عنه ظهور اصوات قليلة وأراء محدودة ، ويرى بعض الباحثين

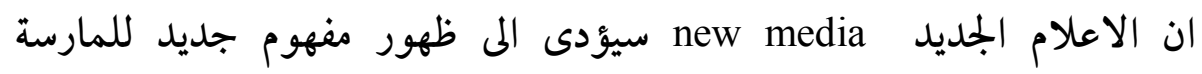

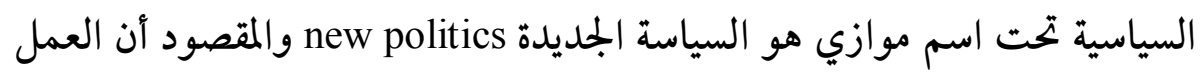

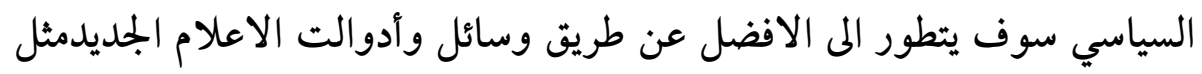

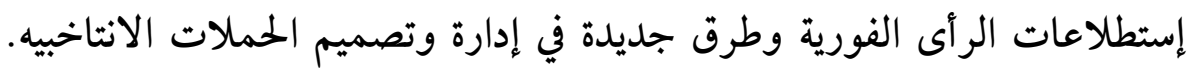

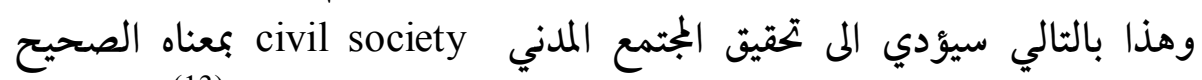

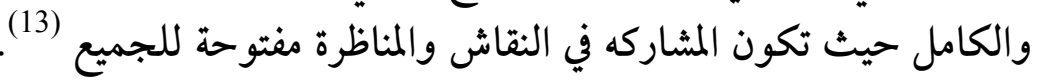

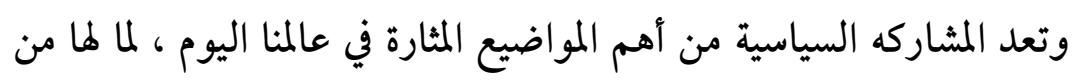

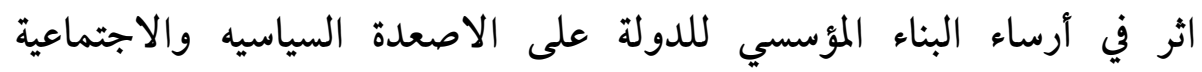

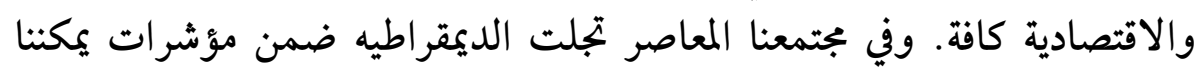

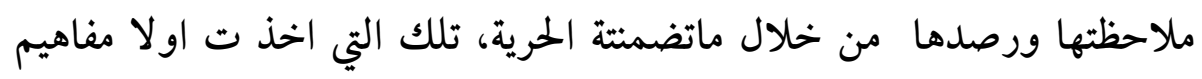

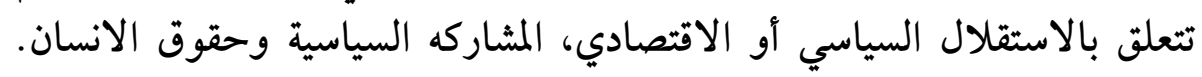

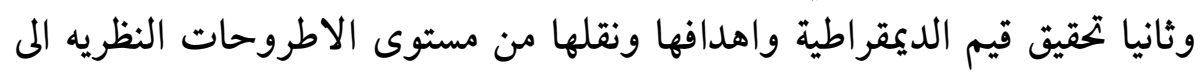

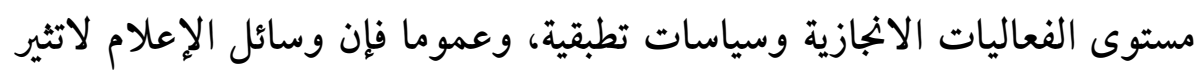




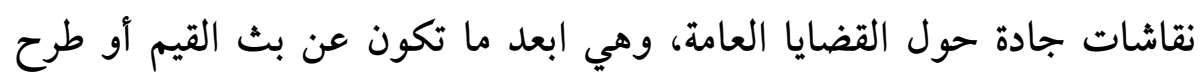

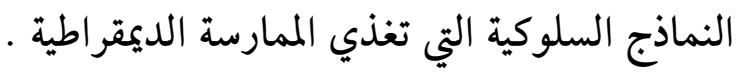

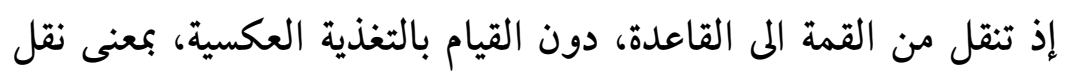

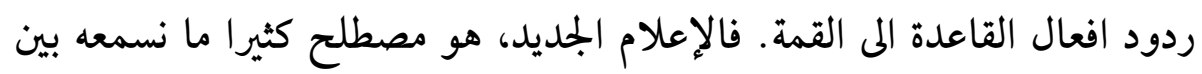

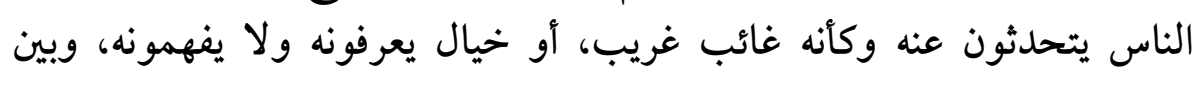

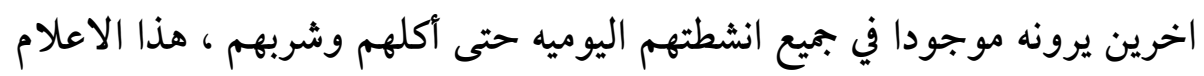

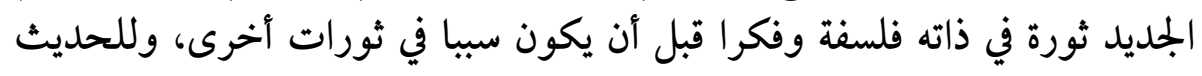

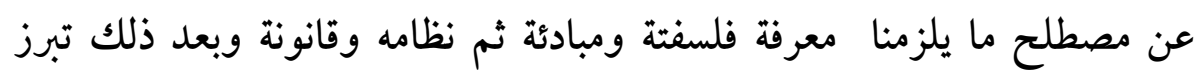

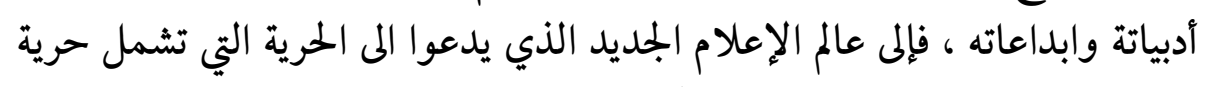

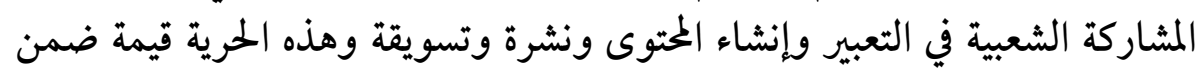

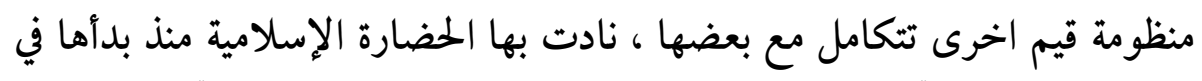

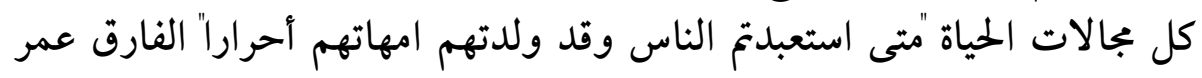

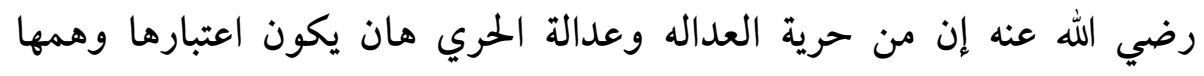

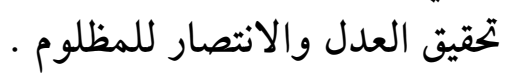

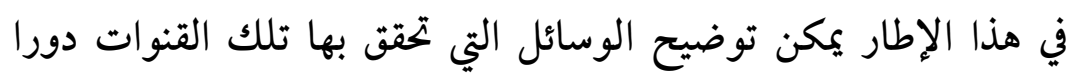

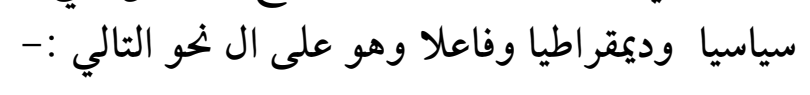

$$
\text { أولا/ دور القنوات الفضائية العربية في تحقيق الديمقراطية : :- }
$$

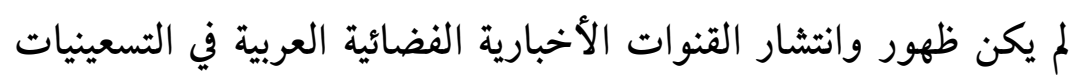

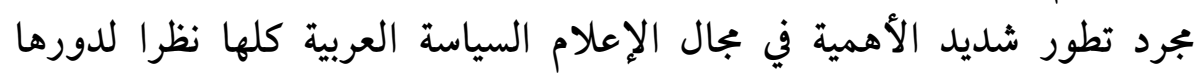

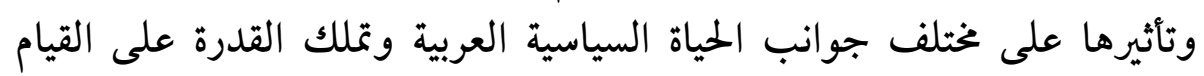

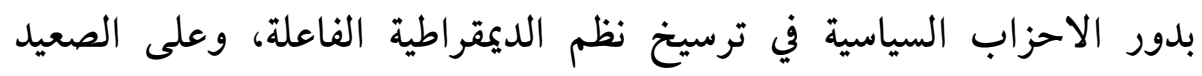

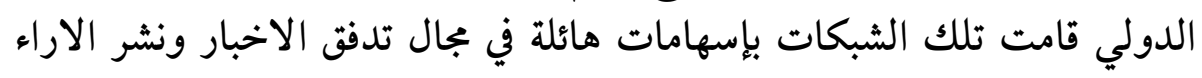

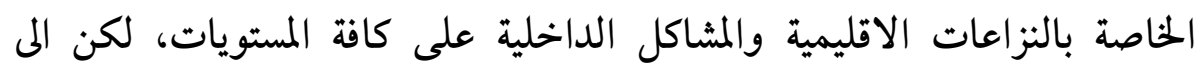

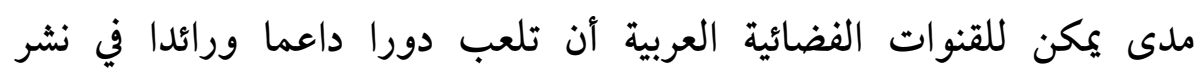


الديمقراطية العربية ؟ وتعتبر القنوات الفضائية وسيلة إعلامية مختلفة عن الإعلام

الحكومي ألمرون

أن الإعلام المرئي والمسموع هو بالحقيقة العنصر الأساسي في تشكيل

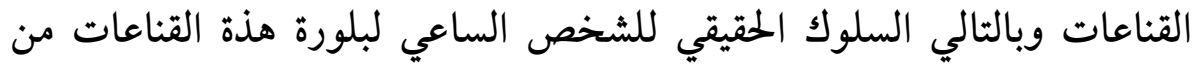

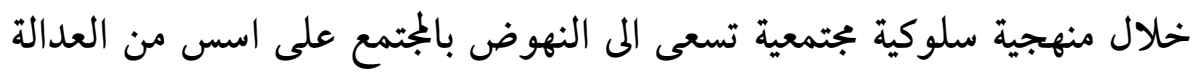

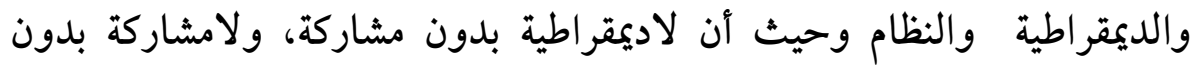

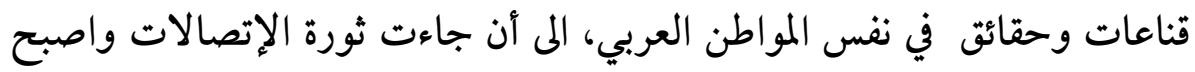

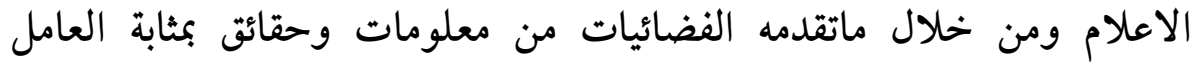
الرئيس في صقل العقول واحداث التغير في العالم العربي.

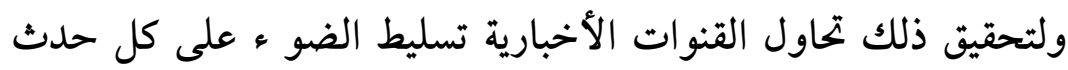

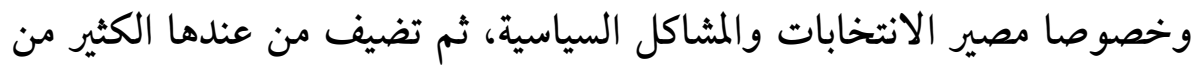

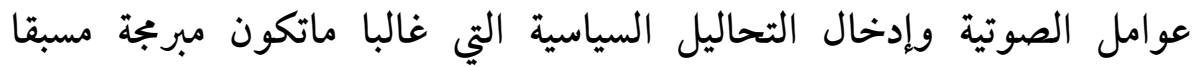

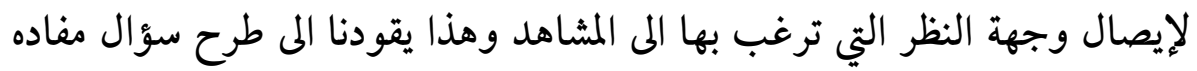

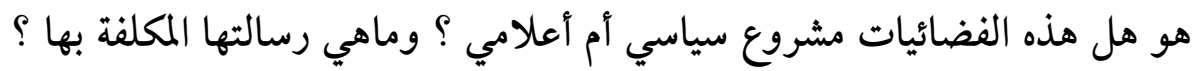

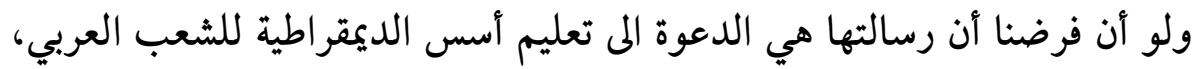

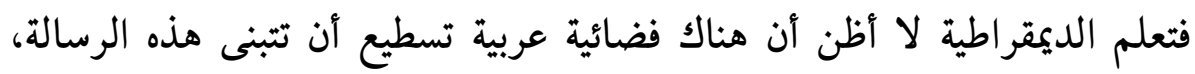

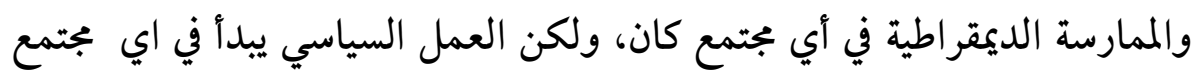
من المجتمعات من خلال الأسرة والمؤسسة التعليمية والأندية الاجتماعية ولاعية وغيرها.

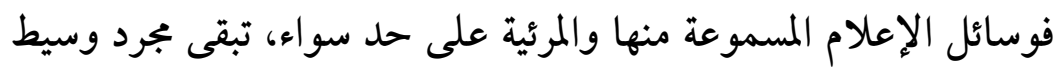

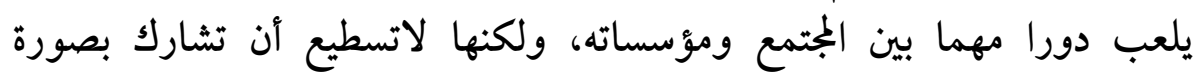

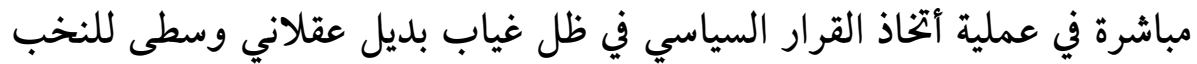
العربيه الحاكمة في المرحلة الحالية (15).

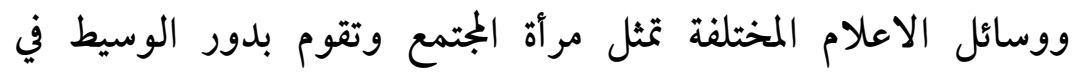
الاتصال السياسي وتساعد في صياغة وتشكيل الحقيقة الديمقراطية التي تمنح 
وسائل الأعلام حرية التعبير عن القضايا التي تثير الجماهير والساسة وصناع

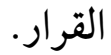

\section{ثانيا/ دور شبكة المعلومات الدولية في تعزيز العمل الديمقراطي :-}

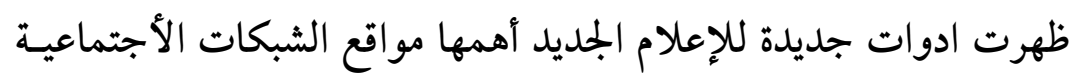

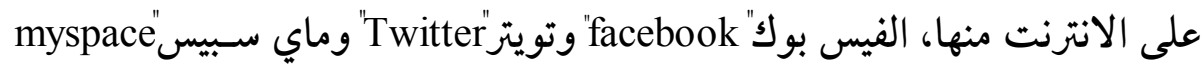

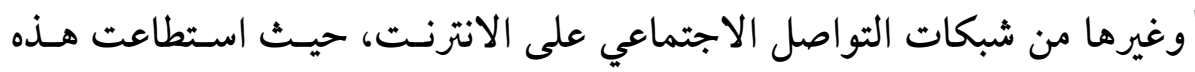

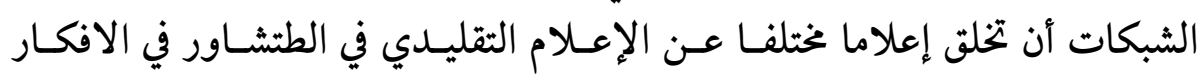

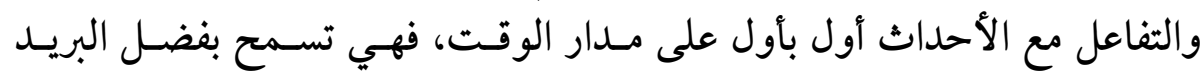

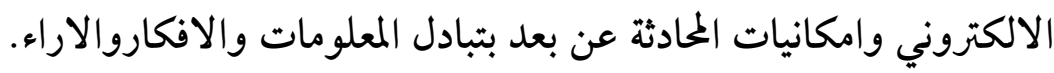

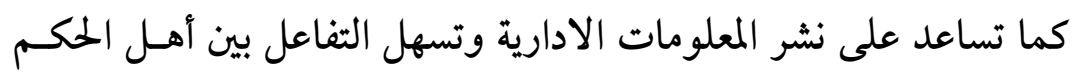

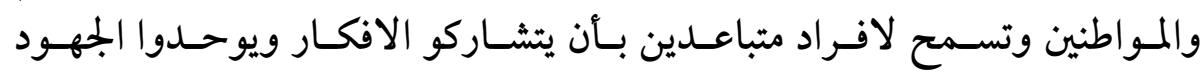

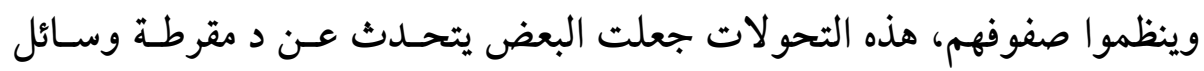

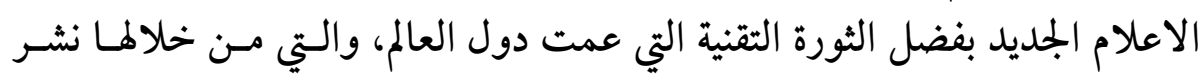

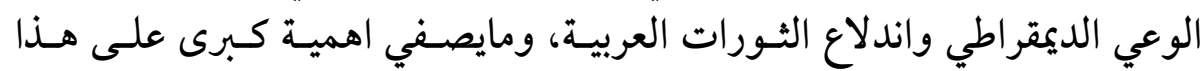

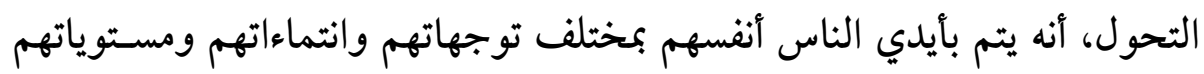

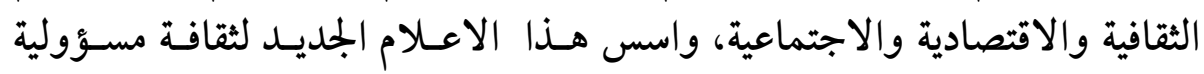

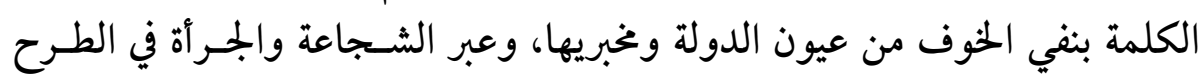
وتحمل مسؤولية حرية التعبير عن الاراء والأفكار.

مما جعل ظهور، شبكة المعلومات الدولية ثورة في مجال تحقيق الديمقراطية الدية

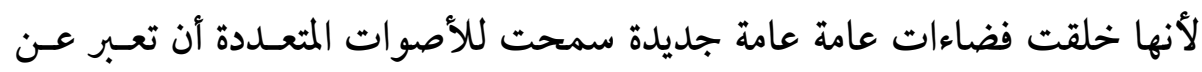

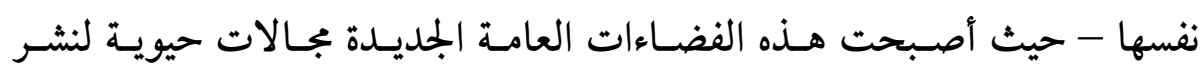

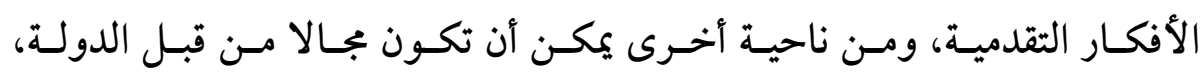

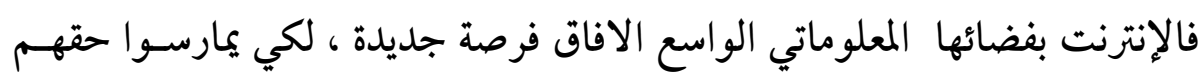

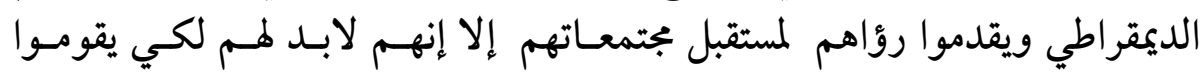

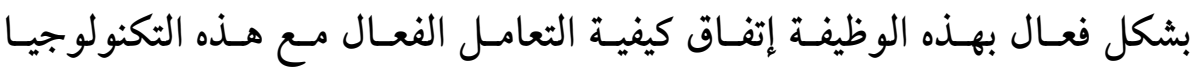


الجديدة، وهذا سيؤدي الم بزوغ نوع جديد مـن انسواع الديقر اطيـة هـي ديمقراطيـة

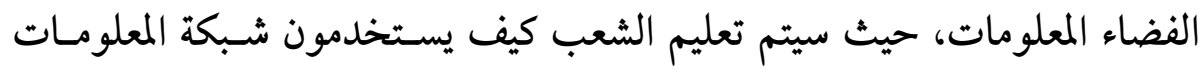

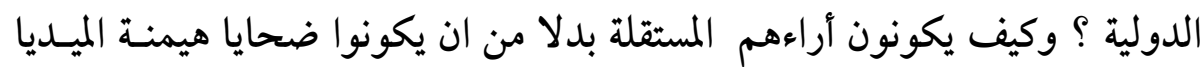

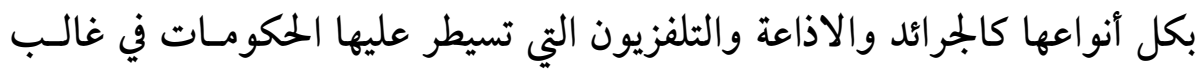

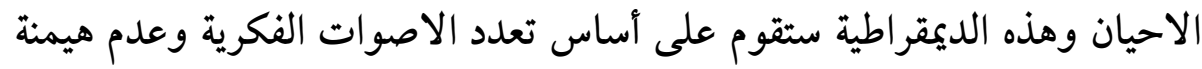

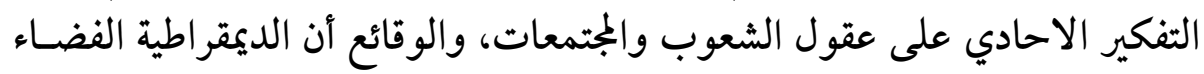

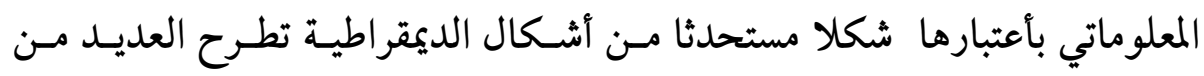
الموضوعات والاراء على كافة الشعب دون استثناء.

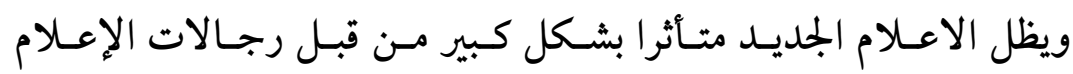

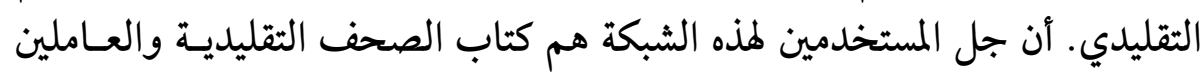

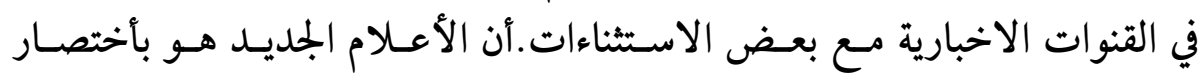

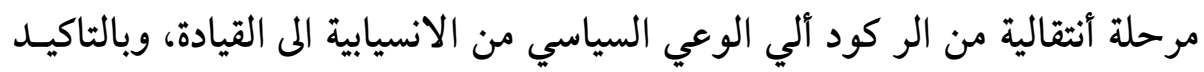
مرحلة انتقالية في تغير شكل الحكومات العرات العربية والمجتمع المدني.

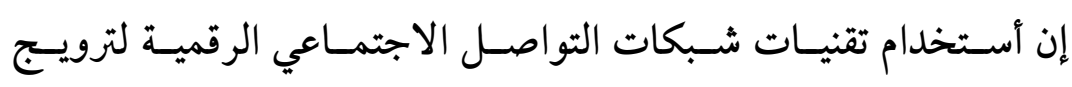

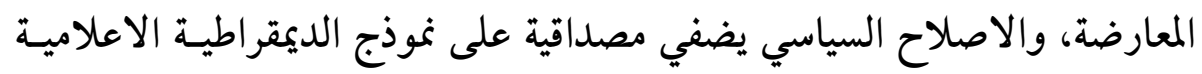

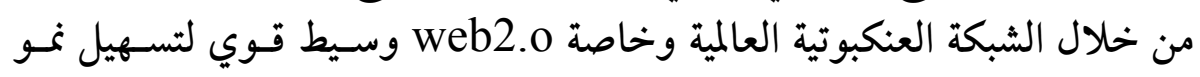

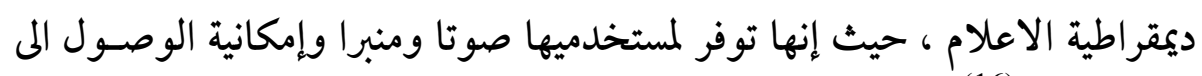
وسيلة أنتاج (16)

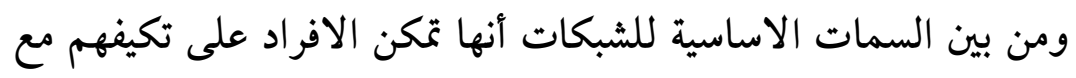

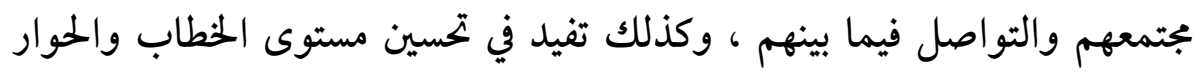

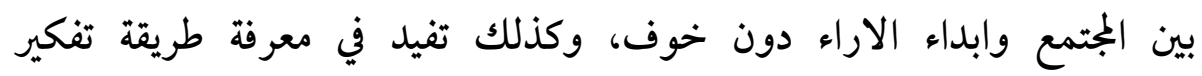

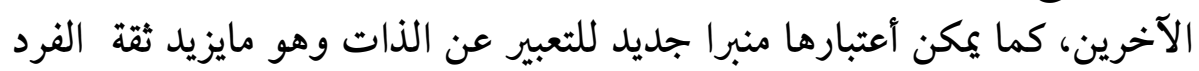

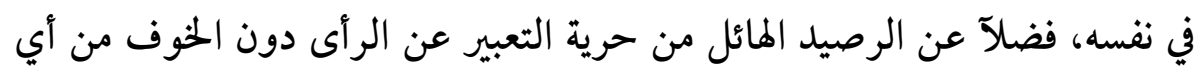

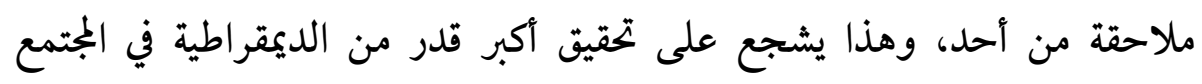


وجعلت من حرية الاعلام حقبة لامفر منها فضلا عن كونها تستند الم اعلام

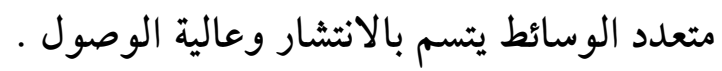

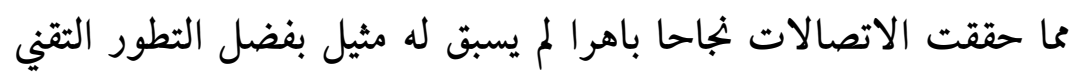

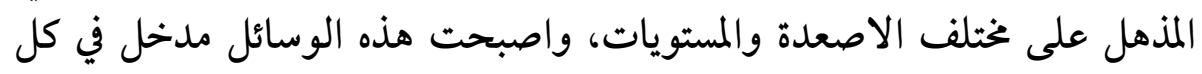

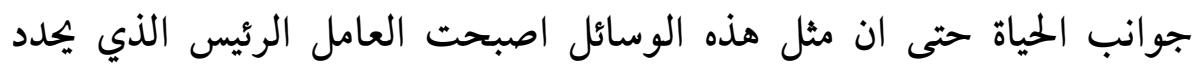

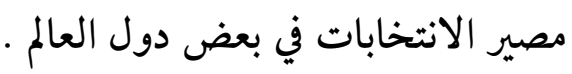

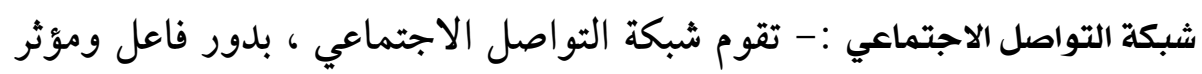

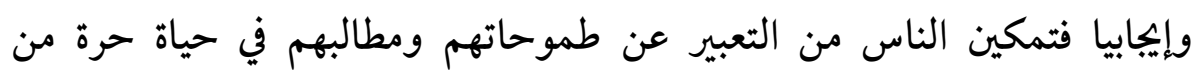

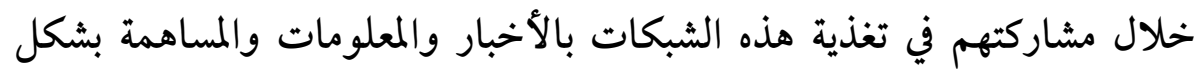

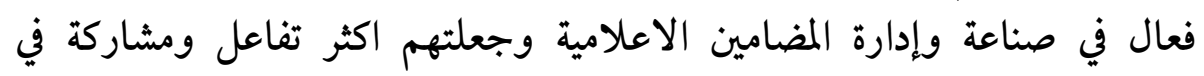

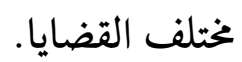

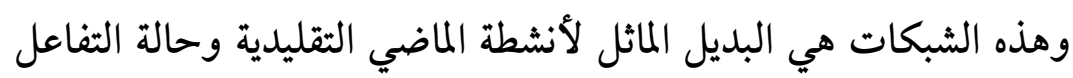

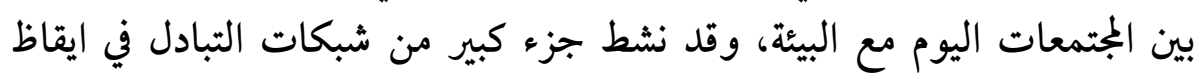

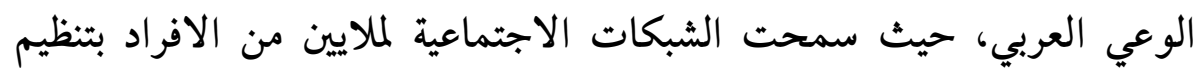

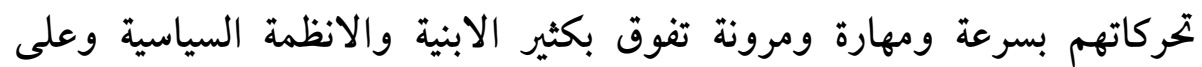
تحقيق المشاركة السياسية بفاعلية .

المبحث الثالث

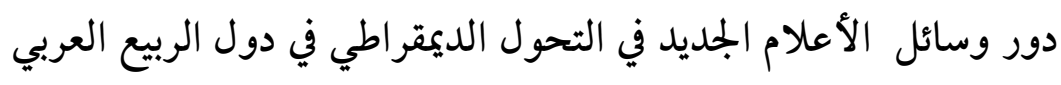

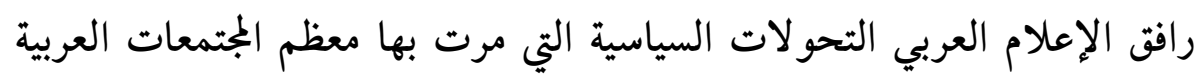

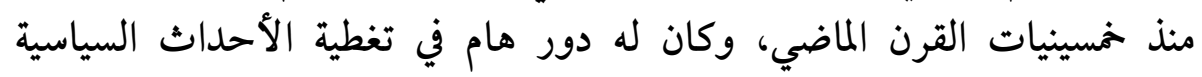

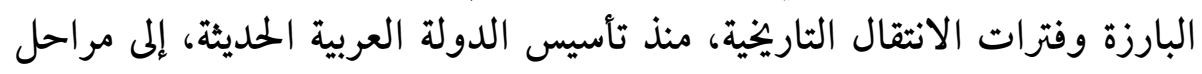

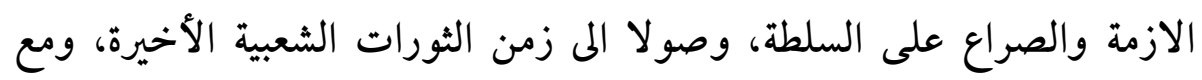

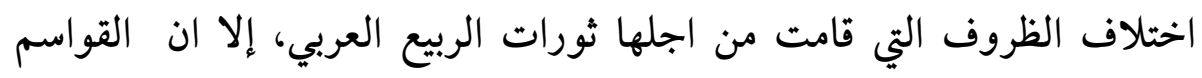

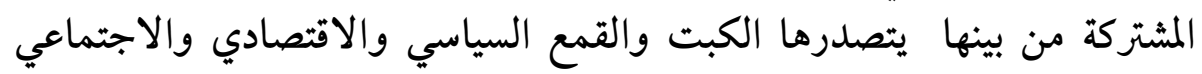

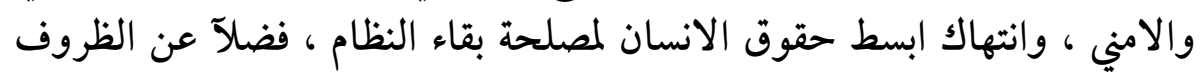




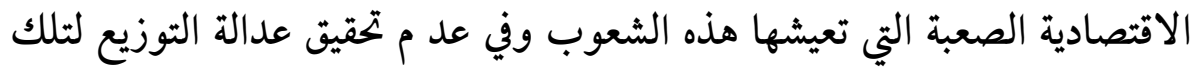

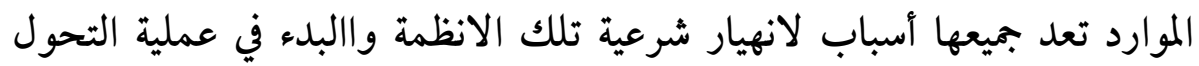

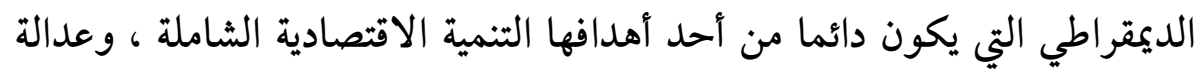

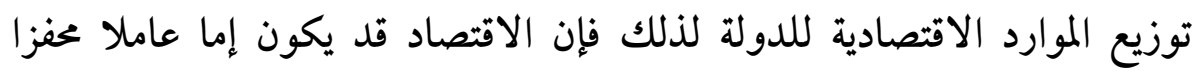

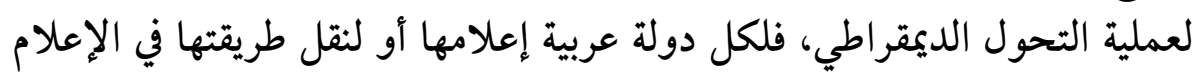
ولكل دولة قنواتها الفضائية العامة والخاصة.

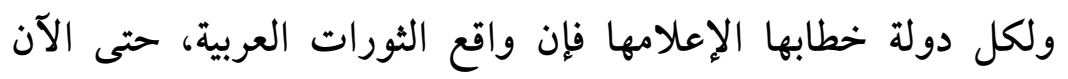

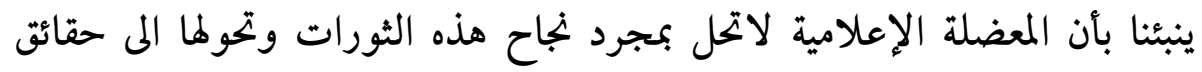

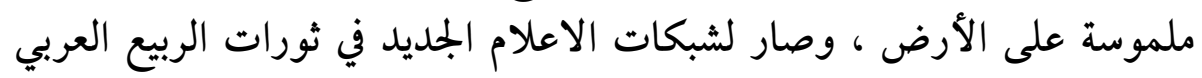

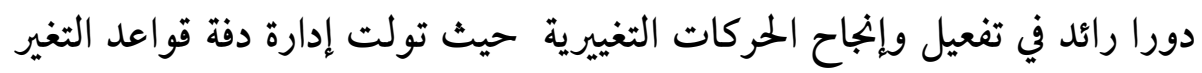

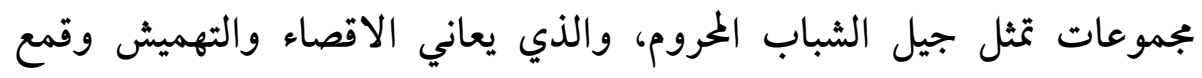

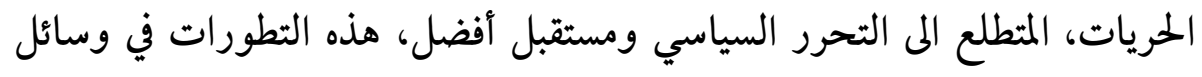

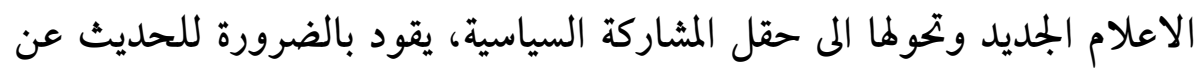

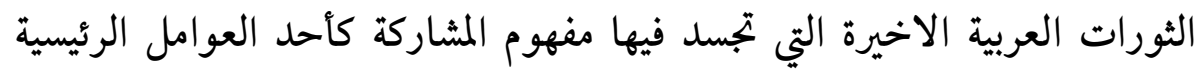

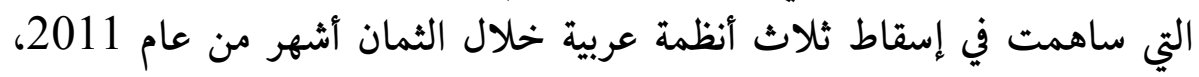

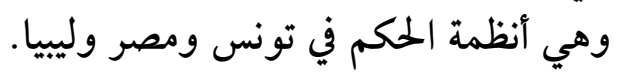

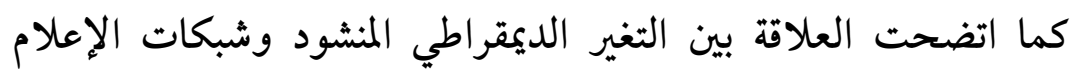

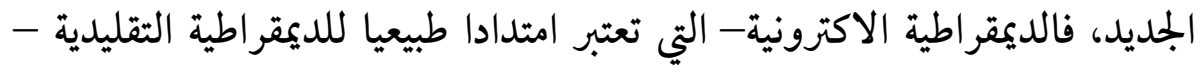

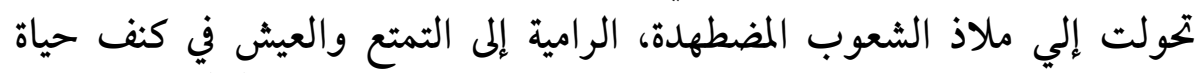

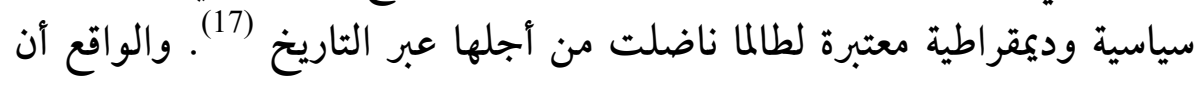

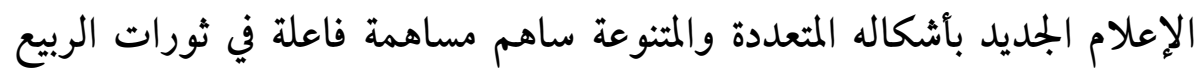

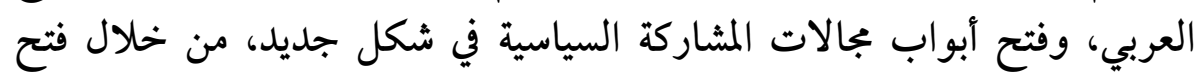

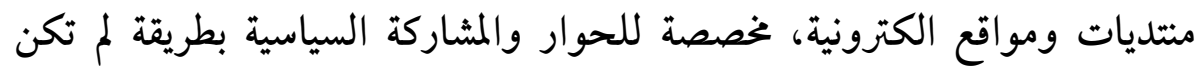

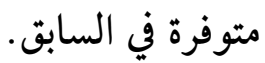


ورفعت هذه الثورات من خلال هذه الشبكات شعارات عديدة متعلقة بالاصلاح السياسي، ومبادى الحرية والعدالة التعددية وينطلق مسارها العملية

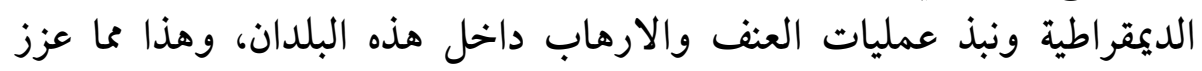

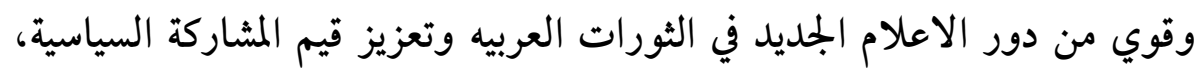

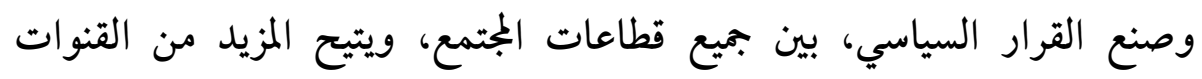

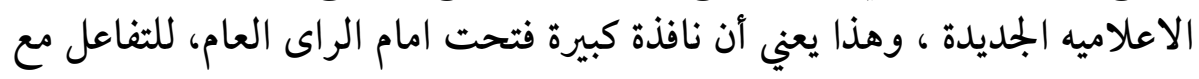

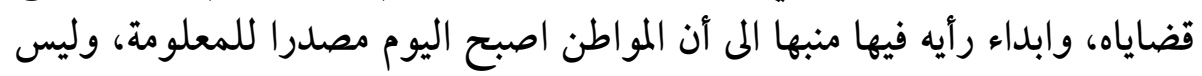

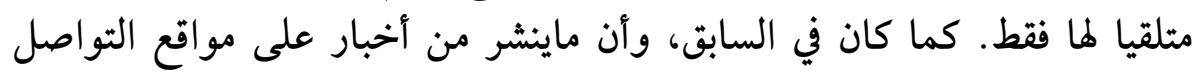

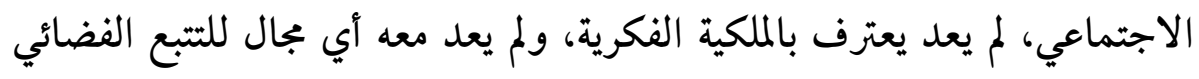

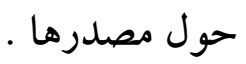


الخاتمة :

صارت وسائل الإعلام الجمديد لها دورا رئيسـا وفـاعلا في تشـكيل سـياق

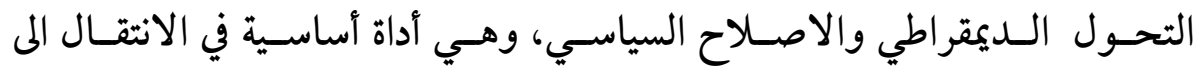

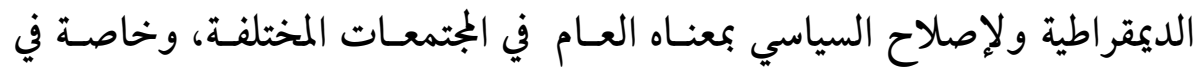

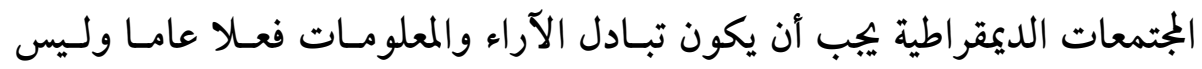

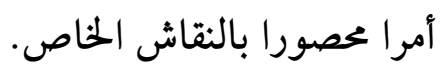

كما لايمكن لحرية التعبير أن تعـزز الحريـات الديمقراطيـة، بشـكل فعـال

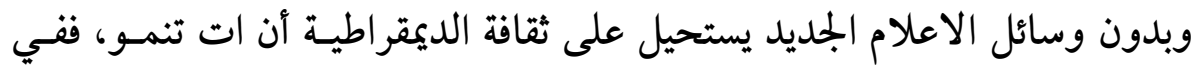

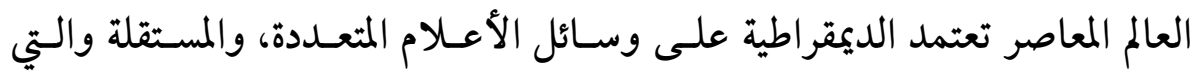

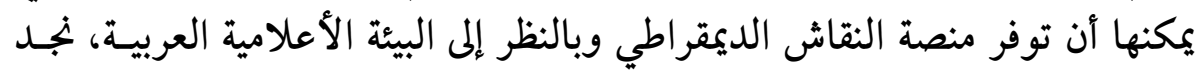

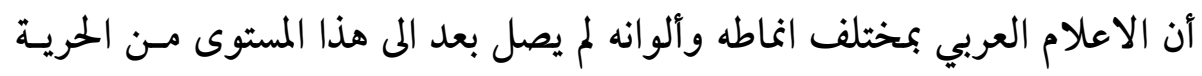

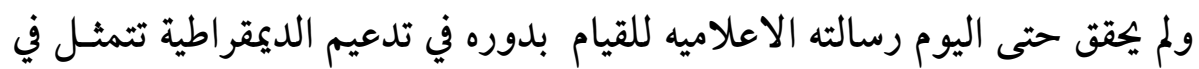
طبيعة العلاقة مع النظام السياسي وكان هذا نتيجة سيطرة مركزية وسـائل الاعـلام

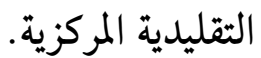

ولكن بفضل التقنية الجيـدة أصسبح بأمكـان الافـراد والمؤسسـات مخاطبـة

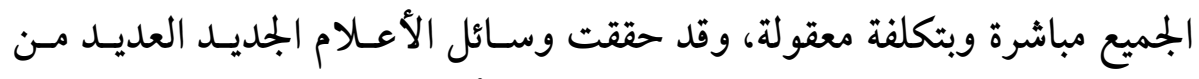

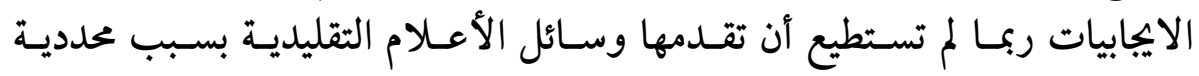

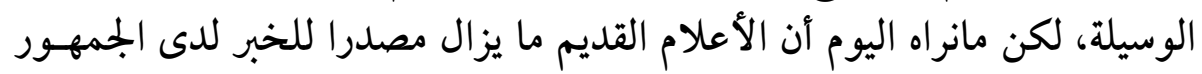
عامة.

وتعـد التقنيـة الحديثـه في وسـائل الإعـلام الجلديـــ جانبـا مهمــا في حيـاة الشعوب في كافة انحاء العالم، وبات تأثيرها يتصدر أحداث الساعة. 


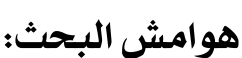

رشاد عبداللطيف، تنمية المجتمع وتضايا العالم التربوية، دار المعرفة الجامعية، ص

$$
\text { بطرس البستاني، محيط المحيط مادة علم ص639. }
$$

رشاد شحاتة أبوريد، مسثولية الإعلام الأسلامى، القاهره، دار الفكر العربي،

$$
\text { .8. 1999، }
$$

أحمد عبدالعزيز المبارك ، اجهزة الاعلام ودورما في توجيه المجتمع، ابوظبي دائرة

$$
\begin{aligned}
& \text { القضاء الشرعي 1977م ص } 67 \text {. } 67 \\
& \text { كمال عفيفي، جريدة الصحافة، } 1971 \text { ، ص26 ـ }
\end{aligned}
$$

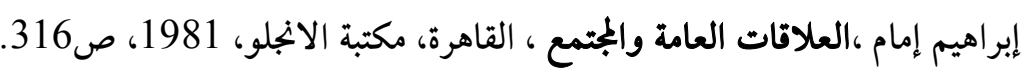
ضوابط الأعلام في الشريعة الإسلامية المملكة العربية السعودية، الرياض، 1979

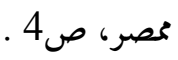

محمد عبد القادر ، دور الأعلام، في التنمية، وزارة الثقافة والأعلام، ص102.

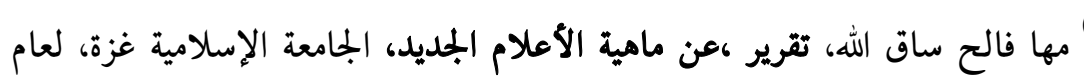

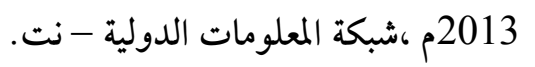

نسرين حسونة، الإعلام الجلديد، المفهوم والوسائل والخصائص والوظائف، مدونة الصحافية، شبكة أمين الإعلامية.

الأعلام الجديد، التصور والمفهوم، Adder Mohammed ألاثنين 10/ 10 / 1 / 2012. فضل الله محمد إسماعيل، رواد الفكر السياسي العربي الحديث، مكتبة المعرفة،

$$
\text { 2006، صن ف220. }
$$

خالد بن عبد الله الحلو، بحث مقدم، في المتندى السنوى السادس للجمعية السعودية

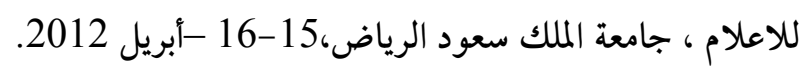

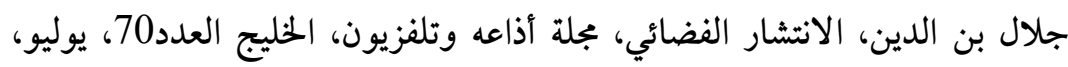

2007، صلال بن الترين، 


\section{العدد 15:.......... جوان 2015}

مفهوم حرية الصحافة، في العالم العربي، الجز الخامس، أرشيف الصحافة والأعلام بتاريخ 27 / 2012 م مورئ

(16)

Kidd Jenny . Are new Media Democratic?

يوسف أزروال، الإعلام الجلديد، وموجة التغير العربي، صحيفة الرؤية، العدد647

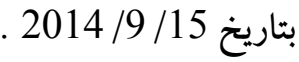

